\title{
Lung function in children of low birth weight
}

\author{
K N CHAN, C M NOBLE-JAMIESON, A ELLIMAN, E M BRYAN, AND M SILVERMAN \\ Department of Paediatrics and Neonatal Medicine, Royal Postgraduate Medical School, Hammersmith \\ Hospital, and Queen Charlotte's Maternity Hospital, London
}

SUMMARY Lung function was recorded in a cohort of 130 age specific children of low birth weight (under $2000 \mathrm{~g}$ ) and a reference population of 120 unselected local schoolchildren at 7 years of age. Children of the cohort were similar in height and forced vital capacity to the reference group, but had significantly reduced forced expiratory volume in 0.75 second and expiratory flow indices. Although neonatal respiratory illness was associated with reduced airway function, we were unable to confirm that this was a consequence of oxygen treatment or mechanical ventilation. Low birth weight, however, was closely associated with poor airway function independent of neonatal respiratory illness. Other factors of importance included the male gender and maternal smoking. The reduction in airway function observed in the low birthweight children was associated with cough but not wheeze. The disparity between the relatively well preserved vital capacity and reduced airway function suggests that very low birth weight, and hence prematurity, has its greatest effect on the subsequent growth of airway function. The absence of an association between neonatal oxygen score or mechanical ventilation and childhood lung function suggests that the long term effect of neonatal respiratory treatment is small compared with that of birth weight, maternal smoking, and male sex.

Preterm infants with neonatal respiratory disorders sometimes sustain severe lung injury during mechanical ventilation. ${ }^{1}$ The resulting clinical syndrome is called bronchopulmonary dysplasia. While it is well established that children who survive bronchopulmonary dysplasia have poor airway function at school age,$^{2-4}$ the long term lung function of most preterm infants who do not develop bronchopulmonary dysplasia has not been settled. Most early studies reported that these children recovered completely and had normal lung function at school age, ${ }^{5-9}$ although some noted subtle abnormalities when more sensitive tests of airway function were used. $^{1011}$ Recent studies have shown increasing evidence of reduced airway function in these children. ${ }^{12-16}$ This disparity may in part be explained by the progressive increase in the survival of very small babies in recent years and in part by the heterogeneity of the study and control subjects in these studies.

Some authors have reported poorer lung function in small groups of children who were born prematurely and who received neonatal respiratory treatment. ${ }^{14} 15$ Defects in study design mean that it is unclear whether their findings were attributable to treatment in the neonatal period or merely to prematurity, as control groups of children of preterm birth who did not require neonatal intensive care were not examined. Some studies had no control groups at all, ${ }^{59} 121416$ whereas others recruited only 'normal' controls rather than a truly representative reference population. In these studies, it is possible that a small difference in airway function between patients and the 'normal' controls was simply a result of selection bias.

Most studies are retrospective. There has been only one large cohort study. ${ }^{9}$ The 153 subjects were recruited over a decade (1961-70) during which techniques of neonatal intensive care changed so much that the subjects were in effect derived from varied neonatal backgrounds.

In order to determine the long term effects of neonatal respiratory treatment on lung function, it is essential to study a large age specific and birthweight specific cohort of preterm children, recruited over a confined time period. The study group should be compared with a reference population of healthy (as opposed to normal) children of equivalent age.

We recently carried out a prospective study of a cohort of low birthweight children at 7 years in order to relate their lung function to birth weight, perinatal factors, and the level of neonatal intensive care 
which they received. We also wished to examine the clinical significance of our findings by relating lung function to current symptoms.

\section{Subjects and methods}

\section{SUBJECTS}

The cohort of low birthweight children and the reference population have previously been described. ${ }^{17}$ Of the 189 survivors of the low birthweight cohort 134 children $(71 \%)$ were available and attended our lung function clinics at 7 years (SD $0 \cdot 2$ years). Because of incoordination $(n=2)$, colds $(n=1)$, and tracheostomy $(n=1)$, only 130 completed the tests. All weighed under $2000 \mathrm{~g}$ at birth, were born between June 1979 and May 1980, and were recruited at birth or on admission to our neonatal units. Perinatal events were recorded at the time the children were discharged home. A reference population of 123 unselected local schoolchildren of equivalent age ( $7 \cdot 0(0 \cdot 4)$ years), none of whom weighed under $2000 \mathrm{~g}$ at birth, were recruited from three schools. Their selection was based on their date of birth irrespective of their previous health or family background.

All the children had lung function tests using an identical protocol and equipment. The standing height of each child was measured without shoes using either a portable or a wall mounted stadiometer (Holtain). A respiratory history was recorded on self administered questionnaires by parents. ${ }^{18}$

The studies were all approved by local ethics committees. Informed consent was obtained from the parents of both the low birthweight cohort and the local schoolchildren.

\section{EQUIPMENT AND PROTOCOL}

Forced vital capacity (FVC) manoeuvres were recorded using a heated pneumotachograph (Fleish No 4) and a microcomputer (Sinclair ZX 48kB). The pressure drop across the pneumotachograph was measured with a differential pressure transducer (Validyne DP45) connected to a carrier demodulator (Validyne). The flow signals were sampled on line with eight bit resolution at at least $70 \mathrm{~Hz}$ by the analog to digital converter and were digitally integrated to produce volume data. The device was linear up to a flow of $9 \mathrm{l} / \mathrm{second}$, encompassing the range of flows encountered during an FVC manoeuvre. Two types of calibration were made. Firstly, the system together with a pocket spirometer (Micro-Medic Ltd), whose measurements were corrected to body temperature, pressure, and saturation, were calibrated with a five litre calibrating syringe at monthly intervals. Because of its low resistance to airflow, the effect of adding the electronic pocket spirometer on the dynamic response of the pneumotachograph was negligible. The two were never found to differ by more than $3 \%$. Secondly, the stability of the system throughout the recording session was checked by recording each blow simultaneously with the pocket spirometer in series with the pneumotachograph. The computer was recalibrated if the readings of the computer and the pocket spirometer differed by more than $2 \%$. At the start of an FVC manoeuvre, data storage commenced when the airflow had exceeded $140 \mathrm{ml} /$ second. Recording ceased as soon as the instantaneous flow fell to zero. The flow-volume curves were displayed graphically on the visual display unit (VDU). Raw data was stored on Microdrive discs (Sinclair) for further analysis.

Before recordings commenced, each child was coached on the technique of the FVC manoeuvre. The subject was seated. A minimum of five FVC manoeuvres were made. Recordings were repeated until at least three technically satisfactory curves were obtained with the FVC within $10 \%$ of the largest value (within $5 \%$ in most cases). Where more than three curves were available, the three with the largest FVC were saved for subsequent analysis. Before calculation of lung function indices the stored flow-volume curves were visually examined for inconsistency by superimposition on the VDU screen. Curves that were affected by technical errors such as noise, hesitancy, and cough were eliminated. The following indices were calculated: FVC, forced expired volume in 0.75 seconds $\left(\mathrm{FEV}_{\mathbf{0 . 7 5}}\right)$, mean transit time, and maximum expiratory flow at 75,50 , and $25 \%$ of FVC remaining in the lungs $\left(\mathrm{MEF}_{75}, \mathrm{MEF}_{50}\right.$, and $\left.\mathrm{MEF}_{25}\right)$. $\mathrm{FEV}_{0.75}$ was used here because many children in the reference group had a forced expiratory time of less than one second. The indices that were obtained from the 'best' curve were used in the analysis. The 'best' curve was defined as the one with the shortest mean transit time, in accordance to recommendations of Chinn and Cotes, ${ }^{19}$ provided that the FVC was within $2 \%$ of that of the largest recorded. In $86 \%$ of cases the 'best' curves were also the ones with the largest sum of FVC and $\mathrm{FEV}_{0.75}$.

DATA ANALYSIS

Reference values for lung function: regression equations

There was a wide range of height among children of both groups (low birth weight 98.8-132.7 cm, control $104 \cdot 0-136 \cdot 0 \mathrm{~cm}$ ). There was also a significant proportion of children of non-white origin, predominantly Asian (Indian subcontinent) and 
Afro-Caribbean (low birthweight $22 \%$, reference $44 \%$ ). In order to facilitate comparison of lung function in the two groups of children, lung function indices were standardised for differences in height, sex and ethnic background, according to guidelines laid down by $\mathrm{Cole}^{20}$ and Quanjer. ${ }^{2 \mathrm{P}}$ Linear, logarithmic, and quadratic models were examined and compared using generalised linear interactive modelling (GLIM). ${ }^{22}$ Only predictors and interaction terms of significance $(p<0.05)$ were retained in the final multiple regression models. Where more than one regression model was found to explain a similar proportion of variance, the simplest one was chosen. The normality and the homosecedasity of the residuals were checked by plotting the residuals against predicted values.

\section{The low birthweight subgroups}

An oxygen score, whose definition has already been detailed, ${ }^{18}$ together with the duration of mechanical ventilation and the peak inspiratory pressure were used as parameters of the level of neonatal respiratory treatment. Lung function was evaluated in the four clinical subgroups, as defined by the level of neonatal respiratory treatment. ${ }^{18}$ Unpaired Student's $t$ tests were used in examining differences between groups. The association between putative risk factors and childhood lung function was evaluated using correlation, one way variance, and multiple regression analysis.

\section{Results}

\section{REFERENCE VALUES FOR LUNG FUNCTION}

Satisfactory lung function recordings were obtained from 120 children of the reference group. Because of the narrow age range, age was not a significant predictor of lung function after adjusting for differences in height. Height, sex, and ethnic background were predictors for FVC, $\mathrm{FEV}_{0.75}$, and $\mathrm{MEF}_{75}$. For $\mathrm{MEF}_{50}$ and $\mathrm{MEF}_{25}$, height and Afro-Caribbean (black) group were significant predictors, whereas for peak expiratory flow rate, sex and height were the only significant predictors. As there was no significant difference in the regression coefficient for covariate height between male and female, and between white and non-white groups, the effects due to differences in sex and ethnic background were best summarised in a single equation for each lung function index as a function of height (table 1). Logarithmic models explained the same proportion of variance as linear models,

Table 1 Standardisation equations for lung function indices derived from the reference population $(n=120)$

\begin{tabular}{|c|c|c|c|}
\hline & & $\begin{array}{l}\text { Residual standard } \\
\text { deviation }\end{array}$ & $r^{2}$ \\
\hline 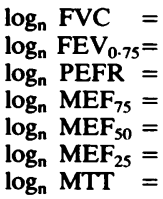 & $\begin{array}{l}-11.08-0.09 \text { 'girl' }-0.16 \text { 'black'-0.08 'Asian' }+2.40 \log _{n} \text { height } \\
-9.41-0.07 \text { 'girl' }-0.14 \text { 'black'-0.09 'Asian' }+2.03 \log _{n} \text { height } \\
-5.97-0.09 \text { 'girl' }+1.50 \log _{n} \text { height } \\
-5.11-0.07 \text { 'girl' }-0.10 \text { 'Asian' }+1.31 \log _{n} \text { height } \\
-5.02-0.11 \text { 'black' }+1.21 \log _{n} \text { height } \\
-6.66-0.17 \text { 'black' }+1.43 \log _{n} \text { height } \\
-5.50+0.95 \log _{n} \text { height }\end{array}$ & $\begin{array}{l}0 \cdot 13 \\
0 \cdot 12 \\
0 \cdot 16 \\
0 \cdot 18 \\
0 \cdot 22 \\
0 \cdot 29 \\
0 \cdot 19\end{array}$ & $\begin{array}{l}0.56 \\
0.53 \\
0.26 \\
0.21 \\
0.09 \\
0.10 \\
0.06\end{array}$ \\
\hline
\end{tabular}

$F V=$ forced vital capacity; $\mathrm{FEV}_{0.75}=$ forced expired volume in 0.75 seconds; $\mathrm{PEFR}=$ peak expiratory flow rate; $\mathrm{MEF}_{75}, \mathrm{MEF}_{50}$, and $\mathrm{MEF}_{25}=$ maximum expiratory flow at 75,50 , and $25 \%$ of FVC; $M T T=$ mean transit time. Units are either l or V/second except MTT which is in seconds.

Table 2 Perinatal data of the low birthweight cohort

\begin{tabular}{|c|c|c|c|c|}
\hline & $\begin{array}{l}\text { No illness } \\
(n=68)\end{array}$ & $\begin{array}{l}\text { Oxygen only } \\
(n=25)\end{array}$ & $\begin{array}{l}\text { Mechanical } \\
\text { ventilation } \\
(n=27)\end{array}$ & $\begin{array}{l}\text { Oxygen } \\
\text { dependence } \\
(n=10)\end{array}$ \\
\hline Median (range) birth weight $(g)$ & $1700(830-1990)$ & $1430(900-1980)$ & $1340(730-1980)$ & $1101(790-1370)$ \\
\hline Median (range) gestational age (weeks) & $33(28-39)$ & $32(27-35)$ & $30(27-34)$ & $28(27-32)$ \\
\hline No (\%) light for dates & $34(50)$ & $6(24)$ & $14(52)$ & $3(30)$ \\
\hline $\begin{array}{l}\text { No (\%) with transient tachypnoea of newborn } \\
\text { No (\%) with idiopathic respiratory distress }\end{array}$ & 5 (7) & $5(20)$ & $10(4)$ & 0 \\
\hline syndrome* & 0 & $11(44)$ & $17(63)$ & $6(60)$ \\
\hline No (\%) with recurrent apnoea or bradycardia & 8 (12) & $10(40)$ & $15(56)$ & $10(100)$ \\
\hline No (\%) with mother who smoked during pregnancy & $18(27)$ & $6(24)$ & $8(31)$ & $4(40)$ \\
\hline
\end{tabular}

${ }^{*}$ Based on radiological diagnosis in the neonatal period. 
but were chosen because the normality and homosecedasity of the residuals were significantly better than for the linear models.

Our prediction equations for lung function indices compared closely with other published data obtained using similar equipment.

\section{PERINATAL DATA AND LUNG FUNCTION}

Important perinatal data for the low birthweight children are summarised in table 2 . Although a large proportion of infants were light for dates, only eight were born at term.

At 7 years the mean height for the low birthweight cohort and the reference group was on the 30th and 50 th centile respectively. Compared with the reference group, the low birthweight children had an equivalent FVC but significantly lower standardised FEV $_{0.75}$ and maximum expiratory flow indices (table 3).

Low birthweight children who received neonatal respiratory treatment had poorer airway function than those who did not $(\mathrm{p}<0 \cdot 01)$. There was, however, no difference between those who received oxygen treatment alone and those who received mechanical ventilation in addition (fig 1). Among those who received oxygen treatment $(n=62)$ and mechanical ventilation in addition $(n=37)$, there was no correlation between the oxygen score, duration or the peak inspiratory pressure of mechanical ventilation, and subsequent airway function.

Airway function at 7 years was strongly correlated with birth weight $(p<0.0001)$ and to a lesser extent gestational age $(p<0 \cdot 05)$. As can be seen from fig 2 , the association between birth weight and $\mathrm{FEV}_{0.75}$

Table 3 Mean height and lung function standardised to a height of $120 \mathrm{~cm}$ in the low birthweight and the reference group. Results are mean (SD)

\begin{tabular}{|c|c|c|}
\hline & $\begin{array}{l}\text { Low birth- } \\
\text { weight group } \\
(n=130)\end{array}$ & $\begin{array}{l}\text { Reference } \\
\text { group } \\
(n=120)\end{array}$ \\
\hline Height $(\mathrm{cm})$ & $119 \cdot 1(5 \cdot 6)$ & $120.4(5.8)$ \\
\hline FVC (l) & $1.39(0 \cdot 24)$ & $1.41(0.21)$ \\
\hline FEV $_{0.75}(1)$ & $1 \cdot 16(0 \cdot 19) \dagger$ & $1.25(0.17)$ \\
\hline PEFR (1/second) & $3.01(0.61) \dagger$ & $3.27(0.52)$ \\
\hline $\mathrm{MEF}_{75}$ (1/second $)$ & $2.69(0.65) \dagger$ & $3.01(0.53)$ \\
\hline $\mathrm{MEF}_{50}$ (1/second) & $1.85(0.54) \dagger$ & $2.15(0.49)$ \\
\hline $\mathrm{MEF}_{25}$ (1/second) & $1.03(0.36) \dagger$ & $1.20(0.36)$ \\
\hline MTT (seconds) & $0.44(0.12) \dagger$ & $0.39(0.07)$ \\
\hline FEV $_{0.75}:$ FVC ratio* & $0.84(0 \cdot 10) \dagger$ & $0.89(0.07)$ \\
\hline
\end{tabular}

$\mathrm{FVC}=$ forced vital capacity; $\mathrm{FEV}_{0.75}=$ forced expired volume in 0.75 seconds; $P E F R=$ peak expiratory flow rate; $M F_{75}, M E F_{50}$, and $\mathrm{MEF}_{25}=$ maximum expiratory flow at 75,50 , and $25 \%$ of FVC; MTT $=$ mean transit time.

*Unstandardised.

†Significance of difference between groups by unpaired $t$ test: $\mathrm{p}<0.001$.
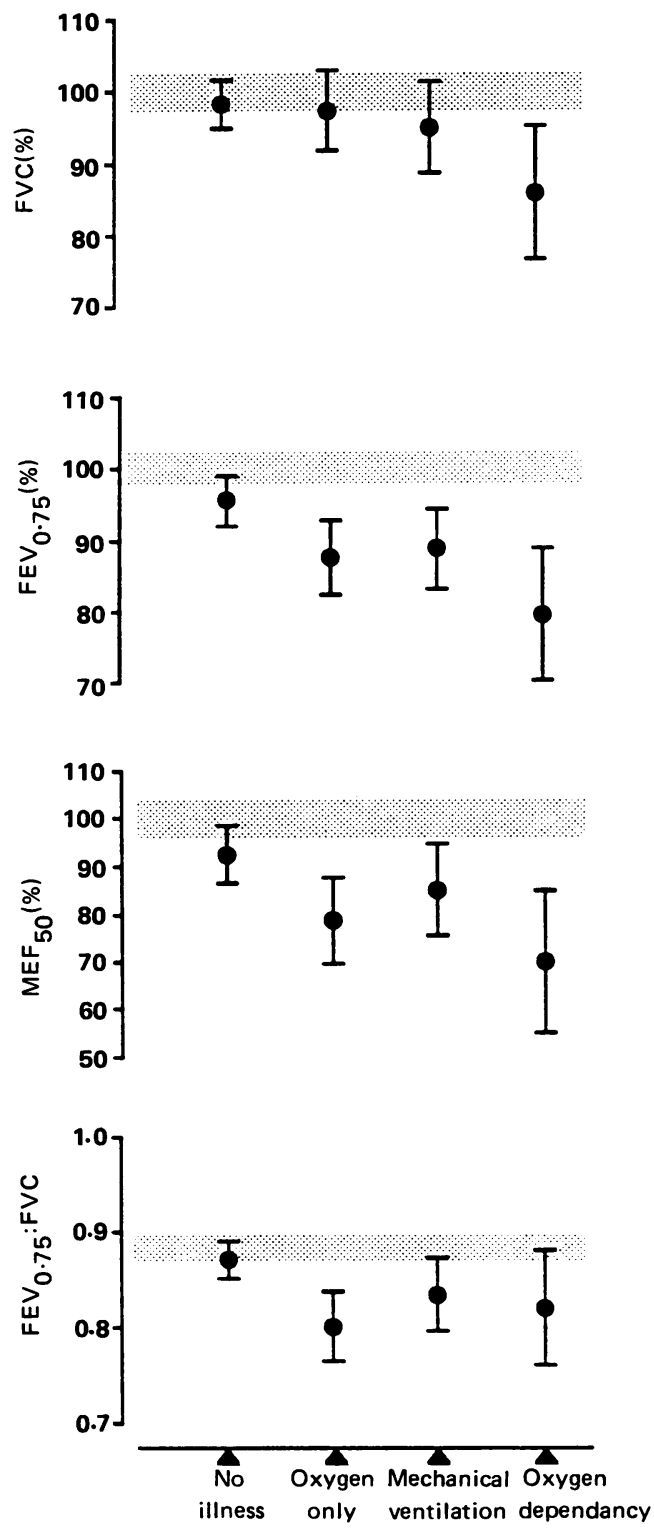

Fig 1 Mean lung function as a percentage of the reference value (and $95 \%$ confidence interval of group mean) for low birthweight children according to clinical subgroup. Sixty eight children received no neonatal respiratory treatment, 25 children received oxygen treatment only, 27 children received mechanical ventilation in addition but did not develop oxygen dependency beyond the neonatal period, and 10 children were still oxygen dependent at 30 days of age.

The $95 \%$ confidence interval of the mean for the reference group is indicated by shaded area. 


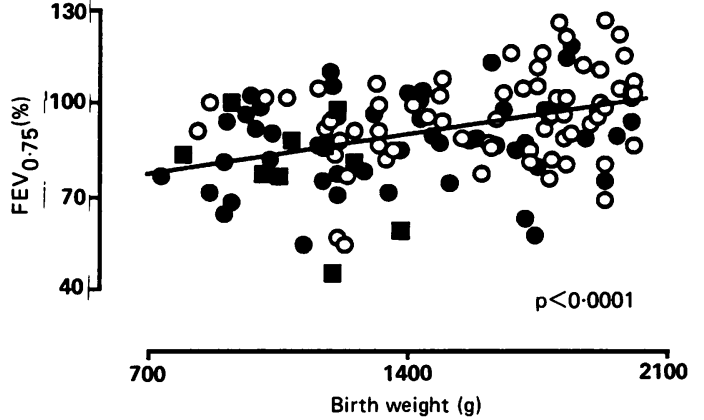

Fig 2 Association between predicted $F E V_{0.75}$

(\% of reference value) at 7 years and birth weight. Open circles: no neonatal respiratory treatment $(n=68)$; closed circles: neonatal respiratory treatment (oxygen and mechanical ventilation combined $(n=52)$;

dark squares: oxygen dependent at 30 days of life $(n=10)$.

was overwhelmingly more significant than that between respiratory illness and airway function. Being light for dates at birth was not associated with a poor outcome. Children who were transferred to our neonatal units after birth had poorer airway function than inborn babies. They were generally of lower birth weight and gestational age than the remainder of the cohort, and this explained the difference.

Boys had a significantly greater reduction in airway function than girls. In our reference group boys had significantly bigger FVC and $\mathrm{FEV}_{0.75}$ for height than girls. In the low birthweight cohort, although the FVC was still larger in boys, they had a marginally lower FEV $_{0.75}$ than girls. Moreover, there was an excess of boys who received neonatal respiratory treatment (boys $60.9 \%$, girls $32.8 \%$, $\chi^{2}=10 \cdot 2, \mathrm{p}<0 \cdot 01$ ) and mechanical ventilation (boys $34 \%$, girls $18 \%, \chi^{2}=4 \cdot 6, p<0 \cdot 05$ ). There was no difference in birth weight and gestational age between boys and girls.
Maternal smoking was also associated with reduced $\mathrm{MEF}_{75}$. The mean value in relation to the predicted value was $80.7 \%$ for those whose mothers smoked and $91.4 \%$ for those whose mothers did not smoke $(\mathrm{p}<0.01)$. The $\mathrm{MEF}_{50}$ and $\mathrm{MEF}_{25}$ were also significantly lower $(\mathrm{p}<0.05)$, but not the $\mathrm{FEV}_{0.75}$. Children of mothers who smoked were also marginally lower in mean (SD) birth weight than the remainder of the cohort (1391 (345) g compared with 1507 (344) g, p=0.08).

As perinatal variables showed varying degrees of correlation between one another, multiple regression analysis was used to examine the association between various independent variables and airway function. It confirmed that the association between $\mathrm{FEV}_{0.75}$ and the two variables, birth weight and the male gender, was not the result of their association with neonatal respiratory illness and treatment. For $\mathrm{MEF}_{75}$, maternal smoking was an additional risk factor of significance.

\section{ASSOCIATION BETWEEN AIRWAY FUNCTION AND SYMPTOMS}

Because some of the questionnaires were not completely filled, full data were available in 121 (91\%) low birthweight children and $100(83 \%)$ children in the reference group for this analysis. Using the same definition for symptoms as in the previous paper, ${ }^{18}$ we found no association between airway function and wheeze. On the other hand, cough was associated with a reduction in airway function (table 4). A weak association between airway function and cough was also present in the reference group.

\section{Discussion}

SOURCES OF BIAS

Previous retrospective studies have the distinct disadvantage that recruitment of study subjects

Table 4 Lung function indices expressed as percent of reference value in children with and without current symptoms at 7 years. Results are mean (SD)

\begin{tabular}{|c|c|c|c|c|c|c|c|c|}
\hline & \multicolumn{4}{|c|}{ Low birthweight group } & \multicolumn{4}{|c|}{ Reference group } \\
\hline & \multicolumn{2}{|l|}{ Wheeze } & \multicolumn{2}{|l|}{ Cough } & \multicolumn{2}{|l|}{ Wheeze } & \multicolumn{2}{|l|}{ Cough } \\
\hline & Yes $(n=19)$ & No $(n=102)$ & Yes $(n=41)$ & No $(n=80)$ & Yes $(n=16)$ & No $(n=84)$ & Yes $(n=17)$ & No $(n=83)$ \\
\hline $\begin{array}{l}\text { FVC } \\
\text { FEV }_{0.75} \\
\text { MEF }_{50}\end{array}$ & $\begin{array}{l}93.5(16 \cdot 4) \\
87.2(14 \cdot 2) \\
78.6(20 \cdot 5)\end{array}$ & $\begin{array}{l}97.4(14.9) \\
92 \cdot 7(15 \cdot 0) \\
88 \cdot 7(26 \cdot 1)\end{array}$ & $\begin{array}{l}94.8(16 \cdot 7) \\
86 \cdot 1(15 \cdot 2)^{* *} \\
78.9(24 \cdot 0)^{*}\end{array}$ & $\begin{array}{l}97 \cdot 8(14 \cdot 3) \\
94 \cdot 8(14 \cdot 0) \\
91 \cdot 3(25 \cdot 4)\end{array}$ & $\begin{array}{l}102.8(16 \cdot 9) \\
98.4(15 \cdot 2) \\
92.5(21 \cdot 3)\end{array}$ & $\begin{array}{l}100 \cdot 0(11 \cdot 7) \\
101 \cdot 5(10 \cdot 2) \\
105 \cdot 1(23 \cdot 5)\end{array}$ & $\begin{array}{l}98 \cdot 7(15 \cdot 6) \\
96 \cdot 3(14 \cdot 7) \\
92.5(20 \cdot 3)^{*}\end{array}$ & $\begin{array}{l}101.4(11.9) \\
101.9(10 \cdot 1) \\
105.3(23.7)\end{array}$ \\
\hline
\end{tabular}

$\mathrm{FVC}=$ forced vital capacity; $\mathrm{FEV}_{0.75}=$ forced expired volume in 0.75 seconds; $\mathrm{MEF}_{50}=$ maximum expiratory flow at $50 \%$ of $\mathrm{FVC}$. Because some of the questionnaires were not completely filled, full data were available in only 121 and 100 children in the low birthweight and the reference groups respectively.

Significance of difference between symptomatic and asymptomatic subjects by unpaired $t$ test: ${ }^{*} \mathrm{p}<0 \cdot 05 ;{ }^{* *} \mathrm{p}<0 \cdot 01$. 
occurred after certain outcome indices, such as the presence or otherwise of idiopathic respiratory distress syndrome or bronchopulmonary dysplasia, were known. Their recruitment was therefore susceptible to bias. Symptomatic subjects or those who have more severe neonatal respiratory illness are often more readily available and willing to participate in studies than are symptom free children. This study is unique in that we prospectively examined the lung function of the survivors of an age specific and birthweight specific cohort of low birthweight children born within a 12 month period, irrespective of neonatal respiratory illness.

Both of the neonatal units participating in this study were neonatal referral centres; $28 \%$ of the low birthweight subjects in our study were outborn, mainly in local hospitals. Consequently our overall findings might be slightly biased towards those with more severe neonatal respiratory illness.

Our reference population was unselected and apart from age, matching was not sought. It comprised more children of ethnic minorities (low birth weight $22 \%$ compared with reference $44 \%$ ) and those whose parents were either unskilled or unemployed (low birth weight 19\% compared with reference $42 \%$ ). Adjustment for differences in ethnic background on lung function was made using multiple regression analysis (table 1). There was no association between airway function and socioeconomic status in either group of children.

In addition to the $\mathbf{3 0}$ low birthweight children who were inaccessible for legitimate reasons (emigration, loss to follow up, etc), an additional 52 subjects in the cohort did not attend our lung function sessions. Two thirds of them lived outside Greater London. There was no difference between those who attended and those who did not with respect to ethnic origin, birth weight, gestational age, and the level of neonatal respiratory treatment received, although 13 of the 23 who had emigrated since discharge were non-white. Their omission was unlikely to have influenced our results.

Neonatal death could have been an important source of bias. Out of the 292 live births and admissions in the cohort, 76 died. If survival were associated with inherently better lung function, then differences in survival rates between different neonatal units, differences in the type of infant population served and the era in which study subjects were born will all add to the difficulties in comparing published studies of lung function in children of low birth weight.

REFERENCE VALUES FOR LUNG FUNCTION

We compiled our own reference values for three important reasons. Firstly, all standards of lung function published so far are based on measurements collected from children with a wide range of ages, with either very few or no young children of an age close to that of our low birthweight cohort. The prediction equations compiled by these studies might be unreliable for young children. Secondly, although ethnic differences on lung function are well known, ${ }^{23}$ most prediction equations published so far apply to white children alone. As $22 \%$ of our low birthweight cohort was non-white, such prediction equations might not be appropriate. Indeed, we too observed significant differences in lung function for height related to ethnic background. The differences observed by us were almost identical to those recently reported in a large sample of non-white children in south London. ${ }^{24}$ Thirdly, by deriving prediction equations from our own reference populations recruited irrespective of their previous respiratory history or environmental and social background, unlike those of previous studies which compared their findings with 'normal' controls, we could be certain that our findings were not biased.

LUNG FUNCTION IN CHILDREN OF LOW BIRTH WEIGHT The low birthweight children had poorer forced expiratory flow indices than the reference group with a well preserved vital capacity. In simple terms, this implies 'obstructive' disease suggestive of airway dysfunction, rather than a 'restrictive' disorder. Airway dysfunction could be a consequence of a multitude of factors such as abnormal intrauterine development, preterm birth, and neonatal respiratory illness or its treatment (fig 3 ). In addition, host factors of genetic origin could directly determine airway function (explaining, for instance, sex and ethnic differences) as well as influencing individual vulnerability to adverse

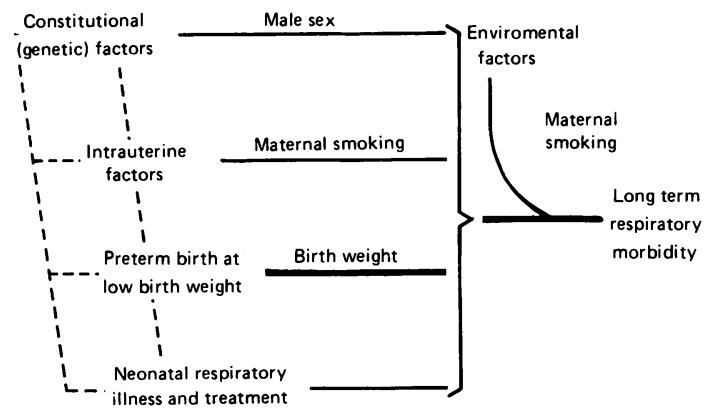

Fig 3 Model of the aetiology of chronic respiratory morbidity. The strength and nature of significant associations that were estimated from the results of the present study are indicated by the width of the lines. Dotted lines represent hypothetical associations. 
environmental factors during infancy and childhood. Male sex was a risk factor of the latter type. The size of this study was not sufficiently large to enable us to determine the relative importance of all these factors with respect to outcome. It did allow us to test the hypothetical association between neonatal respiratory treatment and long term airway function as well as to examine some of the more important factors.

In previous studies, which examine the long term consequences of neonatal respiratory illness and its treatment but without simultaneous examination of preterm children who did not require treatment, ${ }^{14-16}$ it has been assumed that the findings were due to airway 'damage' sustained in the neonatal period. Contrary to such an assumption, our study provided clear evidence for a strong association between airway function and birth weight irrespective of neonatal respiratory illness (fig 2 ). Two previous studies that included a healthy low birthweight control group, have also found poorer airway function with and without neonatal respiratory illness, ${ }^{10} 13$ although these studies were too small to allow for correlation analysis. In contrast with two other studies, ${ }^{1625}$ we were unable to find any association between oxygen score or duration of mechanical ventilation and subsequent airway function in those who received neonatal respiratory treatment. In one of these studies the subjects were probably highly selected, as evidenced by an extraordinarily low mean forced expired volume in one second for the group with respiratory distress syndrome $\left(70 \%\right.$ of predicted) ${ }^{25}$ In our cohort, the mean $\mathrm{FEV}_{\mathbf{0 . 7 5}}$ for the mechanically ventilated group and the group with bronchopulmonary dysplasia was $88.8 \%$ and $79.5 \%$ of predicted respectively. In the other study, ${ }^{16}$ the authors' conclusions did not tally with their own earlier findings on the same subjects. ${ }^{26}$ Their earlier report suggested that, although these children had abnormal lung mechanics in early infancy after neonatal mechanical ventilation, most of them had returned to normal by 0.5 to 1.5 years. At the age of 9 , these children had abnormal airway function that correlated with the duration of mechanical ventilation. It is difficult to reconcile these conflicting results.

The fact that poorer airway function was observed in the very low birthweight children who did not require any form of neonatal respiratory treatment was not due to their smaller size at 7 years. Their body dimensions and FVC were not significantly different from the remainder of the cohort. It is possible that airway growth might be more vulnerable than peripheral lung growth to the adverse effects of very premature birth. Conducting airways and air spaces have a complex embryonic origin. ${ }^{27} 28$
The lungs are only partially developed at term. ${ }^{29} 30$ Multiplication of alveoli takes place in late fetal life as well as postnatally. ${ }^{31}$ Thereafter growth in lung volume is mainly due to increase in their size. It has been suggested that the wide between subject variability in maximum expiratory flow volume curves in healthy subjects is the result of variation in the development of airways in relation to their air spaces. ${ }^{28} 32$ This is termed dysanaptic growth. It is possible that very premature birth that disrupts the normal process of lung growth and development could in some way alter the integrated pattern of growth of the airways and the air spaces. There is as yet no histological study that examines the effect of premature birth itself on the growth of the conducting airways.

The male sex was found to be associated with poor airway function in the low birthweight cohort. In addition, more boys had neonatal respiratory illness and required mechanical ventilation than girls. They also had a slightly poorer survival rate (72\% compared with $78 \%$, inborn and outborn combined). There appears to be a striking parallel between our findings and the observation that respiratory illnesses are commoner in boys during childhood. ${ }^{33} 34$ The male sex might indeed be constitutionally more vulnerable to neonatal respiratory illness and adverse environmental influence.

Maternal smoking, but not smoking by other members of the household, was independently associated with reduction in expiratory flow indices. Such a specific association was not surprising as it has also been observed in larger populations of children. ${ }^{35-37}$ Among all members of the household, mothers are the ones with the most intimate contact with their children. It is, however, surprising that such an effect was detectable in a study as small as ours, as it might be assumed that the effects of neonatal mechnical ventilation and oxygen treatment would be greater than that of cigarette smoke exposure. In the reference group, though children whose mothers smoked also had lower $\mathrm{MEF}_{75}$, the difference was not significant $(p=0 \cdot 17)$. Evidence is accumulating to suggest that the effects of maternal smoking on the respiratory health of their children occur antenatally. ${ }^{38}$ As $92 \%$ and $79 \%$ of the current maternal smokers were smokers before and during their pregnancy respectively, it was not possible to determine, within the size of our cohort, whether the effect of maternal smoking was fetal or postnatal.

OUTCOME FOR BABIES WITH CHRONIC OXYGEN DEPENDENCY (BRONCHOPULMONARY DYSPLASIA) The subgroup with bronchopulmonary dysplasia had 
reduced vital capacity as well as other airway function indices. We do not know whether the reduced FVC was a consequence of restrictive lung disease or of airway obstruction. Their $\mathrm{FEV}_{0.75}$ : FVC ratio was no different from that of the remainder of the cohort (fig 1) and they had no evidence of chest hyperinflation, suggesting that their lungs might be small. There is good morphological data on lung structure in bronchopulmonary dysplasia. Hislop et al found evidence of damage to alveoli (that is, thickened interalveolar septa with increased elastic and fibrous tissue, dilatation of alveolar ducts, and overblown alveoli) in typical cases of bronchopulmonary dysplasia and to a lesser extent in those who required only minimal positive pressure mechanical ventilation. ${ }^{39}$ Such damage might adversely affect lung growth, leading to continued abnormalities in early infancy. ${ }^{40}{ }^{4 P}$ As alveolar development is thought to be completed by about 2 years of age, ${ }^{31}$ complete catch up growth seems unlikely. Indeed severe reduction in the number of alveoli has been observed in cases of bronchopulmonary dysplasia. ${ }^{39} 42$ Alveolar underdevelopment could be an explanation for the small FVC in our survivors who had bronchopulmonary dysplasia. Without knowing the lung size of these infants before neonatal respiratory treatment began, it is a matter of conjecture as to whether the reduction in FVC in these children was a consequence of lung damage resulting from neonatal respiratory support, or whether they had constitutionally smaller lungs than other low birthweight children to begin with, thus accounting for the high level of respiratory treatment that they required in the neonatal period.

In other studies in which pulmonary hypoplasia is suspected in the neonatal period, however, catch up in the growth of lung function seems to occur by the second year of life. ${ }^{43}$ The fact that our subjects had grossly abnormal lung function at the age of 7 years implies additional pathological processes.

As in most other series, bronchopulmonary dysplasia occurred exclusively in very low birthweight subjects (less than $1500 \mathrm{~g}$ ) who required neonatal mechanical ventilation. There was, however, no association between the severity of the initial respiratory illness or the peak inspiratory pressure used and the development of bronchopulmonary dysplasia. Some of those who developed bronchopulmonary dysplasia had relatively mild respiratory illness initially. Six did not require mechanical ventilation in the first 48 hours. Four children did not have respiratory distress syndrome, but were ventilated for respiratory insufficiency and recurre $i$ apnoea. Six children required a maximum inspiratory pressure of only $16 \mathrm{~cm} \mathrm{H}_{2} \mathrm{O}$ or less. In four, the maximum concentration of oxygen given had never exceeded $60 \%$. In contrast, many infants who had severe respiratory distress syndrome and required a high level of oxygen treatment and mechanical ventilation from birth did not progress to develop bronchopulmonary dysplasia.

These findings imply that the children with bronchopulmonary dysplasia might be more vulnerable to the adverse effects of neonatal respiratory treatment. Instead of attributing the poorer airway function in such children to oxygen toxicity or to the effects of barotrauma on immature lungs, our contention is that these children might have had a more vulnerable respiratory system than other very low birthweight children to begin with. Whether the origins of this situation should be sought in fetal life or in the early neonatal period, we cannot tell.

Neonatal complications such as air leak could be important determinants of long term outcome, but because there were only eight survivors who had this particular complication, of whom only five were able to participate in lung function tests, the number was too small to allow for a statistical evaluation. Other putative risk factors such as patent ductus arteriosis and necrotising enterocolitis were also too rare for evaluation.

CLINICAL IMPORTANCE OF REDUCED AIRWAY FUNCTION The strong association between cough and reduction in airway function confirmed the clinical significance of our findings. Within the limitations of our snap shot observations, it is not possible to say whether the reduced airway function observed in these children at 7 years represented the 'end-point' in the development of the lungs. The implications for the development of chronic airflow obstruction in later adult life are unknown. Over the previous few years there had been a progressive reduction in respiratory symptoms in the cohort. From 7 years to adulthood, although lung units do not increase numerically, the FVC increases by as much as 2.5 to 3 fold. ${ }^{27}$ Only longitudinal measurements collected in subsequent years will enable us to determine whether or not the airway function of the low birthweight cohort will show catch up growth and attain a level comparable with the general population.

The implications for prevention are not as clear as one might wish. Firstly, we were unable to show a 'dose-effect' association between neonatal respiratory treatment and childhood lung function. Maternal smoking is the only factor that is potentially amenable to manipulation. Our evidence, added to the formidable published data, ${ }^{38}{ }^{44}$ adds weight to efforts to reduce cigarette consumption by expectant mothers and families with young children. 


\section{Chan, Noble-Jamieson, Elliman, Bryan, and Silverman}

More difficult to achieve, but potentially far greater in its benefits, would be a reduction in preterm birth. In babies of very low birth weight who are at greatest risk, it will be important to identify those factors that predispose to chronic oxygen dependency, bronchopulmonary dysplasia, and subsequent respiratory dysfunction. It is in this group that the greatest returns are to be expected for future investment in research.

We thank the education department of the London Borough of Ealing, the staff and pupils of East Acton First School, Berrymede, and Derwentwater Junior Schools, and the parents and children of the low birthweight cohort for their enthusiastic participation in this project. The work was supported by grants from the Good Neighbour Trust, Moorgate Trust Foundation, C \& A Charitable Trust, Sue Hammerson OBE, the Spastics Society, Fisons Pharmaceuticals, and Glaxo UK.

We also thank Mr V Aber for much helpful statistical advice and Mrs Barbara Reed for organising the lung function clinics. The cohort was initially enrolled due to the efforts of Drs Pamela Davies, David Harvey, and David Starte.

\section{References}

${ }^{1}$ O'Brodovich HM, Mellins RB. Bronchopulmonary dysplasia: unresolved neonatal acute lung injuries. Am Rev Respir Dis 1985;132:694-709.

2 Smyth JA, Tabachnik E, Duncan WJ, et al. Pulmonary function and bronchial hyperreactivity in long-term survivors of bronchopulmonary dysplasia. Pediatrics 1981;68:336-40.

3 Berman W Jr, Katz R, Yabek SM. Long-term follow-up of bronchopulmonary dysplasia. J Pediatr 1986;109:45-50.

4 Bader D, Ramos AD, Lew CD, et al. Childhood sequelae of infant lung disease: exercise and pulmonary function abnormalities after bronchopulmonary dysplasia. J Pediatr 1987;110: 693-9.

5 Lamarre A, Linsao L, Reilly BJ, et al. Residual pulmonary abnormalities in survivors of idiopathic respiratory distress syndrome. Am Rev Respir Dis 1973;108:56-61.

${ }^{6}$ Bryan MH, Levison H, Swyer PR. Pulmonary function in infants and children following the acute neonatal respiratory distress syndrome. Bull Eur Physiopathol Respir 1973;9: $1587-600$

7 Dinwiddie R, Mellor DH, Donaldson SHC, Tunstall ME, Russell G. Quality of survival after artificial ventilation of the newborn. Arch Dis Child 1974;49:703-10.

8 Heldt GP, Mcllroy MB, Hansen TN, et al. Exercise performance of the survivors of hyaline membrane disease. $J$ Pediatr 1980;96:995-9.

9 Stahlman M, Hedvall G, Lindstrom D, et al. Role of hyaline membrane disease in production of later childhood lung abnormalities. Pediatrics 1982;69:572-6.

10 Coates AL, Bergsteinsson $\mathrm{H}$, Desmond $\mathrm{K}$, et al. Long-term pulmonary sequelae of premature birth with and without idiopathic respiratory distress syndrome. J Pediatr 1977;90: 611-6.

11 Coates AL, Desmond K, Willis D, et al. Oxygen therapy and long-term pulmonary outcome of respiratory distress syndrome in newborns. Am J Dis Child 1982;136:892-5.

12 Borkenstein J, Borkenstein M, Rosegger H. Pulmonary function studies in long-term survivors with artificial ventilation in the neonatal period. Acta Paediatr Scand 1980;69:159-63.

13 Mansell AL, Driscoll JM, James LS. Pulmonary follow-up of moderately low birthweight infants with and without respiratory distress syndrome. J Pediatr 1987;110:111-5.
14 Reidel F. Long-term effects of artificial ventilation in neonates. Acta Paediatr Scand 1987;76:24-9.

15 Driscoll DJ, Kleinberg F, Heise CT, et al. Cardiorespiratory function in asymptomatic survivors of neonatal respiratory distress syndrome. Mayo Clin Proc 1987;62:695-700.

16 Andréasson B, Lindroth M, Mortensson W, Svenningsen NW, Jonson B. Lung function eight years after neonatal ventilation. Arch Dis Child 1989;64:108-13.

17 Chan KN, Noble-Jamieson CM, Elliman A, Bryan EM, Aber VR. Airway responsiveness in low birthweight children and their mothers. Arch Dis Child 1988;63:905-10.

${ }^{18}$ Chan KN, Elliman A, Bryan EM, Silverman M. Respiratory symptoms in children of low birth weight. Arch Dis Child 1989;64:1294-304.

19 Chinn DJ, Cotes JE. Transit time analysis of spirograms: which blow is best? Bull Eur Physiopathol Respir 1986;22:461-6.

${ }^{20}$ Cole TJ. Linear and proportional regression models in the prediction of ventilatory function. Journal of the Royal Statistical Society 1968;131:280-302.

21 Quanjer PH, ed. Standardised lung function testing. Report of the working party on standardisation of lung function. European Community for Coal and Steel, Luxembourg. Bull Eur Physiopathol Respir 1983;19 (suppl 5):1-95.

22 Baker RJ. The GLIM system: release 3. London: Royal Statistical Society, 1978.

${ }^{23}$ Cotes JE. Lung function assessment and application in medicine. 4th ed. Oxford: Blackwell Scientific Publications, 1979.

24 Johnston IDA, Bland JM, Anderson HR. Ethnic variation in respiratory morbidity and lung function in childhood. Thorax 1987;42:542-8.

25 Bertrand JM, Riley SP, Popkin J, et al. The long-term pulmonary sequelae of prematurity: the role of familial airwayn hyper-reactivity and respiratory distress syndrome. $N$ Engl Med 1985;312:742-5.

26 Lindroth M, Mortensson W. Long-term follow-up of ventilatore treated low birthweight infants. Acta Paediatr Scand 1986;75; 819-26.

27 Inselman LS, Mellins RB. Growth and development of the lung. $J$ Pediatr 1981;98:1-15.

${ }^{28}$ Green M, Mead J, Turner J. Variability of maximum expiratory flow-volume curves. J Appl Physiol 1974;37:67-72.

${ }^{29}$ Hislop A, Wigglesworth JS, Desai R. Alveolar development in the human fetus and infant. Early Hum Dev 1986;13:1-11.

30 Langston C, Kida K, Reed M, et al. Human lung growth in late gestation and in the neonate. Am Rev Respir Dis 1984;129: 607-13.

31 Thurlbeck WM. Postnatal human lung growth. Thorax 1982;37: 564-71.

32 Mead J. Dysanapsis in normal lungs assessed by the relationship between maximum flow, static recoil and vital capacity. Am Rev Respir Dis 1980;121:339-42.

33 Williams HE, Phelan PD. Respiratory illness in children. Oxford: Blackwell Scientific Publications, 1975.

34 Glezen WP, Denny FW. Epidemiology of acute low respiratory disease in children. $N$ Engl $J$ Med 1973;288:498-505.

35 Tashkin DP, Clark VA, Simmons $M$, et al. The ULCA population studies of chronic obstructive respiratory disease. VII Relationship between parental smoking and children's lung function. Am Rev Respir Dis 1984;129:891-7.

36 Vedal S, Schenker MB, Samet JM, et al. Risk factors for childhood respiratory disease: analysis of pulmonary function. Am Rev Respir Dis 1984;130:187-92.

37 O'Connor GT, Weiss ST, Tager IB, et al. The effect of passive smoking on pulmonary function and non-specific bronchial responsiveness in a population-based sample of children and young adults. Am Rev Respir Dis 1987;135:800-4.

38 Taylor B, Wadsworth J. Maternal smoking during pregnancy and lower respiratory tract illness in early life. Arch Dis Child 1987;62:786-91. 
${ }^{39}$ Hislop A, Wigglesworth JS, Desai R, et al. The effects of preterm delivery and mechanical ventilation on human lung growth. Early Hum Dev 1987;15:147-64.

40 Stocks J, Godfrey S, Reynolds EOR. Airway resistance in infants after various treatments for hyaline membrane disease: special emphasis on prolonged high levels of inspired oxygen. Pediatrics 1978;61:178-83.

41 Wong YC, Beardsmore CS, Silverman M. Pulmonary sequelae of neonatal respiratory distress in very low birthweight infants: a clinical and physiological study. Arch Dis Child 1982;57:418-24.

42 Sobonya RE, Logvinoff MM, Taussig LM, et al. Morphometric analysis of the lung in prolonged bronchopulmonary dysplasia. Pediatr Res 1982;16:969-72.
${ }^{43}$ Helms P, Stocks J. Lung function in infants with congenital pulmonary hypoplasia. J Pediatr 1982;101:918-22.

44 Simpson RJ, Smith NGA. Maternal smoking and low birthweight: implications for antenatal care. J Epidemiol Community Health 1986;40:223-7.

Correspondence to Dr M Silverman, Department of Paediatrics and Neonatal Medicine, Royal Postgraduate Medical School, Hammersmith Hospital, Du Cane Road, London W12 0HS.

Accepted 19 April 1989 